\title{
Facilitators and outcomes of STEM-education groups working toward disciplinary integration
}

\author{
Juliana L. Fuqua, ${ }^{1}$ Jeffrey A. Phillips, ${ }^{2}$ Anna Bargagliotti, ${ }^{3}$ and Dorothea Herreiner ${ }^{4}$ \\ ${ }^{1}$ Department of Psychology and Sociology, California State Polytechnic University, \\ Pomona, 3801 West Temple Avenue; Bldg. 5, Pomona, CA, 91768 \\ ${ }^{2}$ Department of Physics, Loyola Marymount University, 1 LMU Drive; MS-8227, Los Angeles, CA, 90045 \\ ${ }^{3}$ Department of Mathematics, Loyola Marymount University, 1 LMU Drive; STE-2700, Los Angeles, CA, 90045 \\ ${ }^{4}$ Department of Economics, Loyola Marymount University, 1 LMU Drive; STE-4200, Los Angeles, CA, 90045
}

\begin{abstract}
There is a growing societal recognition of the need for transdisciplinary scholarly collaboration which can enhance undergraduate physics, science, and engineering education. A regional conference/network with 100 university education researchers in physics and other STEM fields was formed to address three themes (problemsolving, computational thinking, and equity) with multiple goals including to strive for transdisciplinary publications. As part of an ongoing participant observation study, phone interviews were conducted 3-4 months later. One year later, publications that were completed as a result of the conference were analyzed for their disciplinary integration. The papers showed evidence of interdispliciplanry collaboration but transdiciplinary collaboration proved too difficult to achieve. Multiple factors such as certain facilitating conditions (including lack of prior shared working history, intrapersonal and interpersonal expectations, and sufficient time) may explain why transdisciplinary publications were not developed.
\end{abstract}

\section{INTRODUCTION}

\section{A. Discipine-based education research}

Physics education research (PER) is part of the broader discipline-based education research (DBER), which combines disciplinary knowledge and practices with research on human learning and cognition to address the needs of science, technology, engineering and mathematics (STEM) education. While DBER can be rooted in any discipline, it most often occurs among the STEM disciplines.

While there are many concepts and skills that are common to multiple STEM disciplines, rarely do DBER researchers from different home disciplines collaborate to study them [1]. In fact, within the DBER community there tends to be sharp boundaries between the various disciplines as each communicate in specialized journals and conferences [2]. Breaking across these boundaries within DBER is one of the major challenges facing researchers. The National Research Council has called for more interdisciplinary studies [3]. By integrating multiple disciplines, researchers can examine crosscutting concepts and cognitive processes as well as foster coherence in the student curriculum.

There are some recent examples of disciplinary integration occurring in DBER. For example, the National Experiment in Undergraduate Science Education (NEXUS) is a team of physicists, biologists and chemists collaborating to develop and research innovative curricular materials $[4,5]$. There have been efforts between physics Modelers and biologists to integrate the methods of one community with the content of another [6]. Many physics education researchers focused on the introductory physics for life sciences (IPLS) courses have collaborated with biologists and medical doctors.

At the prior Physics Education Research Conference (PERC) there is some evidence of disciplinary integration. In the 2017 PERC Proceedings, there were 114 contributed papers. Among those papers, nearly half (51) include an au- thor who did not list a physics department in their affiliation. (This number does not include those who do not list a disciplinary department.) The vast majority of these co-authors are housed in centers, departments or schools of education or science education. Twelve papers actually list a co-author who is in a STEM discipline other than physics. While this is a small fraction of the total number of papers it is promising for two reasons: 1 . These are publications targeted at the PER community so one would expect them to focus on singular disciplinary topics, and 2. The fraction has increased since 2007, when only one of the 44 papers included a coauthor from a STEM field other than physics (psychology).

Still, widespread and successful disciplinary integration is challenging. Communication between disparate fields such as physics and cognitive science can be difficult given the differences in content [7]. Among the efforts to catalyze such collaboration is the DBER Alliance [8]. This group of DBER researchers have formed a community to foster online and inperson communication across the disciplines. In addition to that national effort, smaller regional groups have worked to bring researchers from different STEM disciplines together, such as the Breaking Boundaries in STEM Education Research conference discussed below.

\section{B. Conference/network}

Approximately 100 people, from twenty different institutions and representing fifteen different disciplines, attended the National Science Foundation-funded Breaking Boundaries in STEM Education Research one-day conference in April 2017 and are considered part of the ongoing network [9]. The conference and network were constructed around three themes- problem-solving, computational skills, and equity. All three are pressing issues in STEM education and ones that cross disciplinary boundaries. (For additional background on the selection of the themes, 


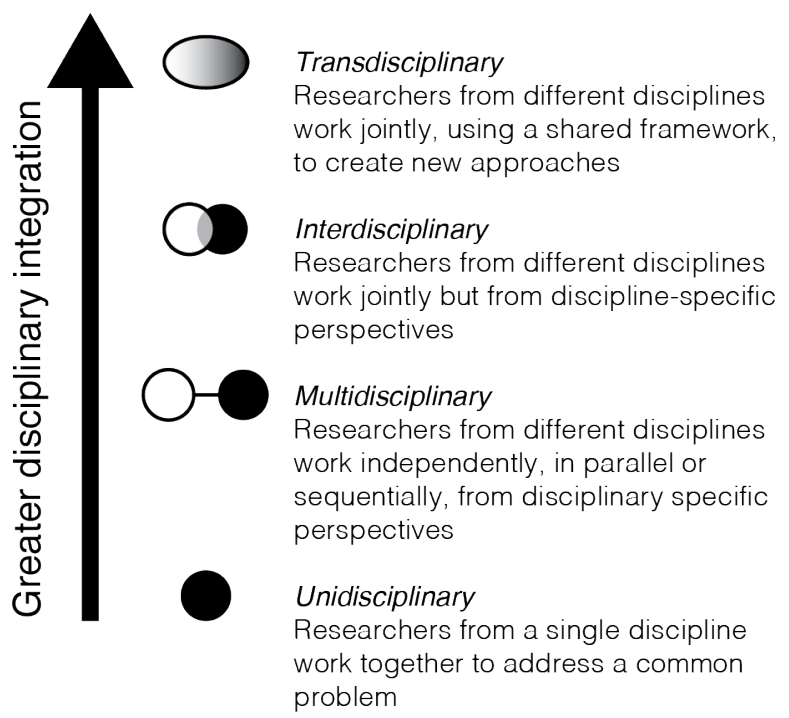

FIG. 1. The disciplinary integration continuum.

please see our previous work [10].)

Aside from several plenary speakers, the conference was divided into three concurrent sessions with each built around one of the themes. The sessions included workshops, contributed presentations and working sessions in which participants were encouraged to begin the collaboration process. In the working sessions, participants shared ideas and spent time discussing what they might want to publish on the theme.

After the conference, attendees were encouraged to continue engaging in scholarly collaboration and to strive for significant disciplinary integration. One year later, multiple journal articles authored by conference attendees were accepted for publication in a dedicated issue of Journal of Research in STEM Education (J-STEM) [11].

\section{Disciplinary integration continuum}

Collaborations (or products) can be placed along a continuum of disciplinary integration depending on characteristics such as the collaborators' backgrounds (Figure 1). On one end, the collaborators share the same disciplinary background and are working solely within one discipline, and therefore no integration occurs. On the other end of the continuum, collaborators come from different disciplines and work to fully integrate their backgrounds into something new.

This continuum can be labeled with several terms to describe the degree to which disciplines are integrated [12]. Unidisciplinary research occurs when researchers from a single discipline work together. Multidisciplinarity occurs when researchers work independently, in parallel, or sequentially from a discipline-specific basis. Interdisciplinarity implies a higher level of interaction, cooperation and creativity across disciplines, and can be defined as research in which researchers work jointly but from a discipline-specific basis.
Transdisciplinarity denotes the highest level of interaction and strongest form of integration, and can be defined as a process by which researchers work jointly using a shared conceptual framework that draws together discipline-specific theories, concepts, and approaches [12]. Transdisciplinary products are not just separate parts added together. Instead they often represent a more holistic product that is greater than the additive sum of parts.

\section{METHODS}

A triangulation of quantitative and qualitative methods were used-analysis of outcomes (publications), behavioral observations of participants at the conference (which confirm our interview results but are not reported in the present paper), and post-conference interviews.

The number and disciplinary integration of the publications that were written as a result of the conference were analyzed. When examining the DBER papers for disciplinary integration, we looked for evidence of multiple perspectives that were used jointly or synthesized into new perspectives.

The post-conference interviews were held by phone, in July/August 2017 , with a select group of 10 participants chosen because they represent a diverse population on several key variables: discipline (e.g., mathematics, physics, computer science, psychology), academic rank (e.g., assistant professor), role (conference organizer, group leader, non-leader), and knowledge of DBER (minimal vs. extensive). Interviews ranged from 20 minutes to over three hours in duration.

Qualitative and quantitative interview questions were selected and adapted from the Perspectives on Transdisciplinary Collaboration, Collaborative Activities Index and interim interview questions of transdisciplinary collaboration, which were developed in a prior study [13]. Questions included: Why did you choose to participate [in the conference]? What were some of the short-term and long-term benefits for you? What do you feel is the most important thing you learned or gained? To what extent did you establish new intellectual linkages with your fellow conference members that may lead to future collaboration together? To what extent did you actually begin collaborating and making intellectual linkages with other conference members as a result of the conference such as working on a publication? (Please see our previous work for additional details on the data collection process [14].)

\section{RESULTS \& DISCUSSION}

\section{A. Number and type of publications}

Six DBER papers were published as a result of the conference (Table I). While papers \#4 \& 5 are descriptions of projects that occur solely within one discipline, the lack of disciplinary integration does not prohibit their connections 
TABLE I. Characteristics of DBER papers resulting from the Breaking Boundaries conference/ network.

\begin{tabular}{|c|c|c|c|c|}
\hline Paper \# & Paper Topic & No. of Authors & Authors' Disciplines & Disciplinary Integration \\
\hline 1 & $\begin{array}{l}\text { Supporting underrepresented students } \\
\text { in STEM }\end{array}$ & 4 & $\begin{array}{l}\text { Physics, Mathematics, Mathematics, } \\
\text { Mathematics }\end{array}$ & Multidisciplinary \\
\hline 2 & $\begin{array}{l}\text { Encouraging breadth through cross- } \\
\text { disciplinary programs }\end{array}$ & 2 & Computer Science, Statistics & Interdisciplinary \\
\hline 3 & $\begin{array}{l}\text { Characteristics of good problems and } \\
\text { how to use them }\end{array}$ & 6 & $\begin{array}{l}\text { Mathematics, Biology, Chemistry, } \\
\text { Chemistry, Mathematics, Physics }\end{array}$ & Interdisciplinary \\
\hline 4 & $\begin{array}{l}\text { Student-student communication while } \\
\text { problem-solving }\end{array}$ & 1 & Mathematics & Unidisciplinary \\
\hline 5 & $\begin{array}{l}\text { Using and teaching reflective appren- } \\
\text { ticeship in graduate courses }\end{array}$ & 1 & Mathematics & Unidisciplinary \\
\hline 6 & $\begin{array}{l}\text { Computing in undergraduate STEM } \\
\text { courses }\end{array}$ & 4 & $\begin{array}{l}\text { Biology, Computer Science, Com- } \\
\text { puter Science, Mathematics }\end{array}$ & Multidisciplinary \\
\hline
\end{tabular}

with other disciplines in the future as many projects that integrate multiple disciplines begin as unidisciplinary projects.

Paper \#6 presents three case studies of computing experiences at three different institutions. Each case study was written independently of the others and shows no evidence of integrating the disciplinary perspectives. The absence of any discussion, and a very minimal conclusion section, indicate that the three sets of ideas were not integrated and instead remain independent of each other.

In paper \#1, the authors describe two programs that support underrepresented students in STEM. The majority of the paper describes the two programs in parallel with some highlighting of common features in the discussion portion. While this global perspective does appear in interdisciplinary works, the lack of any clear integration of STEM disciplinary perspectives does indicate that this paper is multidisciplinary.

Paper \#2 is similar to papers \#4 \& 5 in that it focuses on a single project. Yet in paper \#2, the authors combine to address a shared problem-the lack of breadth in a traditional BS degree. Computer scientists and statisticians worked together to create a minor in Data Science that is viable for students in multiple STEM majors. One significant difference between this paper and \#1 \& 6 is that this project has been ongoing for several years. This duration would seem to have allowed paper \#2's co-authors to have significant integration.

Paper \#3 is one that came the closest to meeting the goals of the Breaking Boundaries conference in that it tackled the cross-cutting problem of problem-solving and brought together a collection of faculty from a wide range of universities, who had not previously written together. As with papers \#1 \& 6, paper \#3 also presents case studies from various disciplines. However, paper \#3 more extensively integrates the disciplinary perspectives to achieve interdisciplinarity. Paper \#3 does not quite achieve transdisciplinarity as the authors have not gone beyond the shared disciplinary ideas to create new models or language regarding problem-solving. Rather, the authors seem to be working to find the common features that already exist within their disciplinary perspectives.
One different feature of paper \#3's authors is that one has a broad disciplinary background - degrees from several different STEM fields and prior co-authorship with authors whose discipline are different than her/ his own. It is hypothesized that this experience made it easier for the author to integrate disciplinary perspectives. Also, several of the authors had additional contact with each other at a second conference, which helped to deepen the disciplinary integration.

A couple themes emerged about publications that resulted from the Breaking Bounds conference/network. First, it was difficult for groups to complete many publications. The quantity of publications that were completed as a result of the Breaking Boundaries conference/network was considered encouraging, but small in number, according to conference organizers. Eight publications were completed. Two were authored by conference organizers about the conference, and the remaining 6 publications were related to DBER. In the interviews, the conference organizers and some attendees mentioned that although it is great for several publications be developed as a result of the conference, they hoped that 12 or more publications would have resulted.

Second, it was difficult for groups to achieve transdisciplinary scholarly collaboration. As shown in Table I, the publications included unidisciplinary, multidisciplinary, and interdisciplinary work, but not transdisciplinarity. Only one publication, \#3, was close to being considered transdisciplinary. It was typical for group members to think about their own discipline's approach to a theme, and then for each to write their ideas in chunks, with each member adding a chunk. They did not integrate ideas and develop innovations that are indicative of transdisciplinary works. (However, multidisciplinary works can evolve into transdisciplinary works.)

\section{B. Facilitators to publishing transdisciplinary papers}

Multiple factors can explain why some individuals publish more than others as they strive toward transdisciplinarity [15- 
17]. In prior research on the Breaking Boundaries collaborations, we found that groups with certain characteristics such as a narrower disciplinary span, strong and motivated leadership presence, a shared history, a leader with a strong recent history of publishing were more ready to collaborate and publish [14]. Such groups experienced faster, smooth-running progress toward publishing. These themes are also evident one year later after publications have been completed.

Expectations and attitudes of group members also matter. According to the interview data, some members did not have a strong desire to work on interdisciplinary publications or any publications at all, and they did not publish. Other members came to the conference with well thought-out ideas of interdisciplinary papers they wanted to write with others. Those members were more likely to publish, especially when they had strong desire, expectations, and perceived reward for publishing (e.g., academic promotion)

Paper champions are needed. There were relatively few paper champions or people who wanted to organize and lead a paper. One of the three theme working groups of the conference did not develop any publication plan, by the end of the conference. The other two working groups had paper champions and were more productive at publishing.

Effective leadership and communication of expectations are needed from organizers. Some non-publishing members and working group leaders said they were not clear about what was expected or desired by the conference organizers. Advance warning and guidance to help them lead a multiple discipline paper was desired by members.

Establishing intellectual linkages across different disciplines requires extensive time. Members commented that one day is not enough time for discussion of ideas and planning many papers. In fact research suggests a ten-year span is needed to see the benefits of some transdisciplinary endeavors such as large centers [18].

More unstructured time, such as quiet free time and breaks, to let ideas mesh during conferences may help group members with the difficult process of planning papers that integrate multiple disciplines. The conference did not include optional times and locations for people to sit, think, and write. Some members said that they needed time for mental rest, to have time to contemplate and let ideas percolate.

Some people had a positive orientation to collaborating across disciplines, known as transdisciplinary ethic [19]. Their inclusive thinking, open-minded stance, optimism and stamina in the pursuit of transdisciplinary research goals, and desire for methodological pluralism, can facilitate transdisciplinary collaboration.

\section{CONCLUSIONS}

The Breaking Boundaries conference is an example of a conference event and network format that that has great potential for DBER researchers. In a short amount of time, they published some papers, albeit not transdisciplinary papers. In order to fully integrate ideas from different disciplines and achieve transdisciplinarity, certain factors and conditions may be necessary, such as more time together than a one-day event (and loosely organized network). Additional research is needed to identify other factors that facilitate and hinder transdisciplinary collaborative endeavors, so that physics educators can develop innovations such as new ideas and publications, with DBER researchers from different disciplines.

Simply having a paper authored by researchers from different disciplines does not ensure that the various perspectives have been integrated. Only when the diverse conceptual and methodological approaches of each discipline are utilized and integrated can the researchers achieve the type of crosscutting work called for by the National Research Council.

\section{ACKNOWLEDGMENTS}

This work is supported by the National Science Foundation (\#1644470).
[1] C. Henderson et al., J. Eng. Educ., 106, 349 (2017).

[2] V. Talanquer, J. Res. Sci. Teach., 51, 809 (2014).

[3] National Research Council, Discipline-Based education research: Understanding and improving learning in undergraduate science and engineering (The National Academies Press, Washington, DC, 2012).

[4] E. F. Redish et al., Am. J. Phys. 82, 368 (2014).

[5] E. F. Redish and T J. Cooke, CBE-Life Sci. Educ., 12, 175 (2013).

[6] S. Matheny and E., Brewe, CBE-Life Sci. Educ., 12, 206 (2013).

[7] C. Henderson, J. P. Mestre, and L. L. Slakey, Policy Insights Behav. Brain Sci., 2, 51 (2015).

[8] http://www.trelliscience.com/DBER-A/

[9] http://www.lmu.edu/breakingboundaries
[10] A. Bargagliotti, D. Herreiner and J A. Phillips, J. Res. STEM Educ., 4, 2 (2018).

[11] http://j-stem.net/vol4no1-2018_special-issue/

[12] P. L. Rosenfeld, Soc. Sci. Med., 35, 1343 (1992).

[13] J. Fuqua et al., in Urban Health and Society: Interdisciplinary Approaches to Research and Practice, edited by N. Freudenberg, S. Saegert, and S. Klitzman (John Wiley \& Sons, 2009), p 185.

[14] J. L. Fuqua et al., J. Res. STEM Educ., 4, 37 (2018).

[15] J. L. Fuqua Ph.D. thesis, University of California at Irvine, (2002).

[16] D. Stokols et al., Am. J. Prev. Med., 35,96. (2008).

[17] D. Stokols et al., Am. J. Prev. Med., 28, 202. (2005).

[18] K. Hall et al., Am. J. Prev. Med., 42, 157 (2012).

[19] D. Stokols et al., Nicotine Tob. Res., 5, S21 (2003). 